\title{
Review Article \\ Role of IL-38 and Its Related Cytokines in Inflammation
}

\author{
Xianli Yuan, Xiao Peng, Yan Li, and Mingcai Li \\ Zhejiang Provincial Key Laboratory of Pathophysiology, Department of Immunology, Ningbo University School of Medicine, \\ Ningbo 315211, China \\ Correspondence should be addressed to Yan Li; liyan@nbu.edu.cn and Mingcai Li; limingcai@nbu.edu.cn
}

Received 31 May 2014; Accepted 13 October 2014

Academic Editor: Jose C. Rosa Neto

Copyright (C) 2015 Xianli Yuan et al. This is an open access article distributed under the Creative Commons Attribution License, which permits unrestricted use, distribution, and reproduction in any medium, provided the original work is properly cited.

Interleukin- (IL-) 38 is a recently discovered cytokine and is the tenth member of the IL-1 cytokine family. IL-38 shares structural features with IL-1 receptor antagonist (IL-1Ra) and IL-36Ra. IL-36R is the specific receptor of IL-38, a partial receptor antagonist of IL-36. IL-38 inhibits the production of T-cell cytokines IL-17 and IL-22. IL-38 also inhibits the production of IL-8 induced by IL$36 \gamma$, thus inhibiting inflammatory responses. IL-38-related cytokines, including IL-1Ra and IL-36Ra, are involved in the regulation of inflammation and immune responses. The study of IL-38 and IL-38-related cytokines might provide new insights for developing anti-inflammatory treatments in the near future.

\section{Introduction}

Our understanding of the interleukin-1 family (IL-1F) has recently expanded to encompass 11 members: IL-1F1-IL-1F11 [1]. These cytokines are also termed IL- $1 \alpha$, IL-1 $\beta$, IL-1 receptor antagonist (IL-1Ra), IL-18, IL-36Ra, IL-36 $\alpha$, IL-37, IL-36 $\beta$, IL-36 $\gamma$, IL-38, and IL-33, respectively [2] (Table 1). These protein molecules play a prominent role in inflammation and immune responses, acting as the first line of defense against invasive pathogenic microorganisms and physical damage. IL-38 is a novel member of the IL-1F identified in 2001 by a unique high throughput cDNA screening approach taking advantage of a set of oligonucleotide probes to hybridize successive arrays of human cDNAs from various tissues $[3,4]$. The former name of IL-38 is IL-1HY2, similar to IL-36Ra (IL1HY1). IL-38 is the 10th member of IL-1F and its receptor is termed IL-1 receptor-related protein 2 (IL-1Rrp2, IL-36R). IL38 is an IL-36 antagonist and functions as a typical receptor antagonist similar to IL-1Ra and IL-36Ra [5]. IL-38 reduces inflammation by preventing the binding of agonist receptor ligands to IL-36R, a specific receptor of IL-38.

\section{Biological Characteristics of IL-38}

The novel IL-1-like gene, IL-38, is located in the IL-1 family cluster (except $I L-18$ and $I L-33$ ) on human chromosome 2q13-14.1 near the IL-1Ra gene (IL-1RN) and IL-36Ra gene $(I L-36 R N)$ [6]. The $I L-38$ gene is located 49,479 bp upstream from $I L-1 R N$ on the same DNA strand [7]. IL-38 shares high sequence homology with $I L-1 R a$ and $I L-36 R a$. The primary translated product is an IL-38 precursor, 152 amino acids in length and with $16.9 \mathrm{kD}$ molecular mass. Sequence analysis indicated that the IL-38 protein shares $41 \%$ homology with IL-1Ra and 43\% homology with IL-36Ra $[4,7]$ and lower homology (14-30\%) with IL-1 $\beta$ and other IL-1 family proteins. In mammalian Chinese hamster ovary cells, recombinant IL-38 protein was synthesized into two forms, a major form at $25 \mathrm{kD}$ and a minor form at $17 \mathrm{kD}$. Lin et al. [3] suggested that the major form of IL-38 might be a result of posttranslational protein modifications, such as phosphorylation. However, studies have shown that the IL-38 protein lacks $\mathrm{N}$-glycosylation and $\mathrm{O}$-glycosylation consensus sites in Chinese hamster ovary cells [3]. As is typical of the IL-1 family, including IL-36Ra, IL-36 $\alpha$, IL-36 $\beta$, and IL-36 $\gamma$, IL-38 lacks a signal peptide and caspase- 1 consensus cleavage site $[3,7]$. Furthermore, the natural $\mathrm{N}$ terminus for IL-38 is still unclear [7]. Using the multiple alignment sequence profile-based searching method (PSI-BLAST), an automated sequence and structure searching procedure (high throughput modeling), and a fold recognition method (SeqFold), three-dimensional structural models of IL-38 were predicted. The IL-38 structural model displays a $12-\beta$-stranded trefoil 
TABLE 1: IL-1 family members $[10,11]$.

\begin{tabular}{|c|c|c|c|c|}
\hline Cytokine & Family name & Receptor & Coreceptor & Property \\
\hline IL-1 $\alpha$ & IL-1F1 & IL-1RI & IL-1RAcp & Proinflammatory \\
\hline IL-1 $\beta$ & IL-1F2 & IL-1RI & IL-1RAcp & Proinflammatory \\
\hline IL-1Ra & IL-1F3 & IL-1RI & NA & Antagonist for IL- $1 \alpha$, IL-1 $\beta$ \\
\hline IL-18 & IL-1F4 & IL- $18 \mathrm{R} \alpha$ & IL- $18 R \beta$ & Proinflammatory \\
\hline IL-36Ra & IL-1F5 & IL-36R & NA & Antagonist for IL-36 $\alpha$, IL-36 $\beta$, and IL-36 $\gamma$ \\
\hline IL-36 $\alpha$ & IL-1F6 & IL-36R & IL-1RAcp & Proinflammatory \\
\hline IL-37 & IL-1F7 & IL-18R $\alpha ?$ & Unknown & Anti-inflammatory, transcription regulating factor [12] \\
\hline IL-36 $\beta$ & IL-1F8 & IL-36R & IL-1RAcp & Proinflammatory \\
\hline IL-36 $\gamma$ & IL-1F9 & IL-36R & IL-1RAcp & Proinflammatory \\
\hline IL-38 & IL-1F10 & IL-36R & Unknown & Antagonist for IL-36 $\alpha$, IL-36 $\beta$, and IL-36 $\gamma$ \\
\hline IL-33 & IL-1F11 & ST2 & IL-1RAcp & Proinflammatory, transcription regulating factor [13] \\
\hline
\end{tabular}

NA: not applicable; ?: requires confirmation.

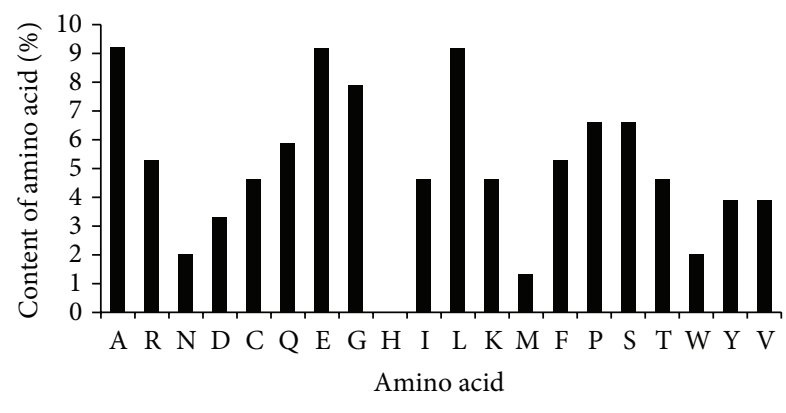

FIgURe 1: Amino acid composition of human IL-38 protein.

structure and shares similarity with the crystal structure of IL-1Ra and IL-1 $\beta[3,8]$. The characteristics of IL-38 provide further evidence that it belongs to the IL-1F. In addition, IL38 was categorized in the IL-36 subfamily according to the length of its precursor. Thus, IL-38 likely also belongs to this subfamily because it has the ability to bind to the common receptor IL-36R $[2,9]$.

To date, no reports have described the components and properties of IL-38. We adopted the ProtParam tool $[14,15]$ application to analyze the amino acid composition of IL-38, which consists of 19 amino acids. A (alanine), E (glutamic acid), and L (leucine) were the most prevalent amino acids (9.2\%) in IL-38, followed by G (glycine, 7.9\%), P (proline, $6.6 \%$ ), and $\mathrm{S}$ (serine, 6.6\%). Only $\mathrm{H}$ (histidine) was not present in IL-38 (Figure 1). The molecular weight of IL38 is $16.9 \mathrm{kD}$ and is consistent with a previous study, as predicted by ProtParam tool. IL-38 has a half-life of $7 \mathrm{~h}$, an isoelectric point $(\mathrm{pI})$ of 4.94 , and the molecular formula of $\mathrm{C}_{757} \mathrm{H}_{1164} \mathrm{~N}_{198} \mathrm{O}_{226} \mathrm{~S}_{9}$, as analyzed by SOPMA (selfoptimized prediction method from alignment) $[15,16]$. Moreover, the second structure of IL-38 was composed of a $\beta$-turn, random coil, $\beta$-sheet, and $\alpha$-helix. Analysis further indicated that the random coil and $\beta$-sheet were uniformly distributed in the protein chain.

By multitissue first-strand cDNA PCR analysis, IL-38 mRNA was measured in a range of tissues, including heart, placenta, fetal liver, skin, spleen, thymus, and tonsil. IL-38 was expressed mostly in the skin and in proliferating B cells of the tonsil [3]. However, in nonimmune tissues, such as human heart and placenta, IL-38 was present at low levels, similar to other IL-1F members [7]. Some IL-1F members are constitutively produced, whereas others have inducible expression, being rapidly induced by bacteria or inflammatory mediators $[7,17,18]$. The expression type of IL-38 is currently unknown and requires further research.

\section{Receptor and Signaling Pathway of IL-38}

In 2001, it was speculated that IL-38 acted as an IL-1 receptor antagonist because of its amino acid homology to the naturally occurring IL-1Ra and the observation that IL-38 could bind to the soluble IL-1 receptor type I (IL-1RI). IL$1 R I$ was once considered a receptor for IL-38 [3,5]. However, the binding affinity of recombinant IL-38 is significantly lower than that of IL-1Ra and IL-1 $\beta$. Recently, researchers doubted whether IL-1RI was a receptor for IL-38. IL-1Rrp2 was regarded as an IL-38-specific receptor and was also called IL-36R. In a report by van de Veerdonk [5], the combining capacity between IL-38 and IL-1RI, IL-36R, IL-18R, and IL$1 \mathrm{R}$ accessory proteins (IL-1RAP, IL-1RAcP) was compared, in the presence of increasing concentrations of IL-38. IL-38 bound to IL-36R but did not bind to the other immobilized receptors. Furthermore, IL-38 binding to immobilized IL$36 \mathrm{R}$ was comparable to IL-36Ra binding to the same receptor. It was observed that increasing the concentration of IL-38 resulted in increased optical density, reaching a plateau at $16.7 \mu \mathrm{g} / \mathrm{mL}$, a higher value than that obtained for IL-36Ra. Based on the binding studies, these data suggest IL-38 could act by blocking the IL-36R pathway.

The most recently identified IL-1 family members are widely expressed in inflammatory cells. These cytokines combine with the cell-surface receptor IL-1R and induce downstream signaling, including downstream nuclear transcripts such as nuclear factor- $\kappa \mathrm{B}$ (NF- $\kappa \mathrm{B})$ and activator protein-1 (AP-1). Furthermore, as a feedback and adjustment mechanism, these signaling molecules induced the expression of cyclooxygenase, nitric oxide synthase, and other inflammatory mediators to promote the development of inflammation 


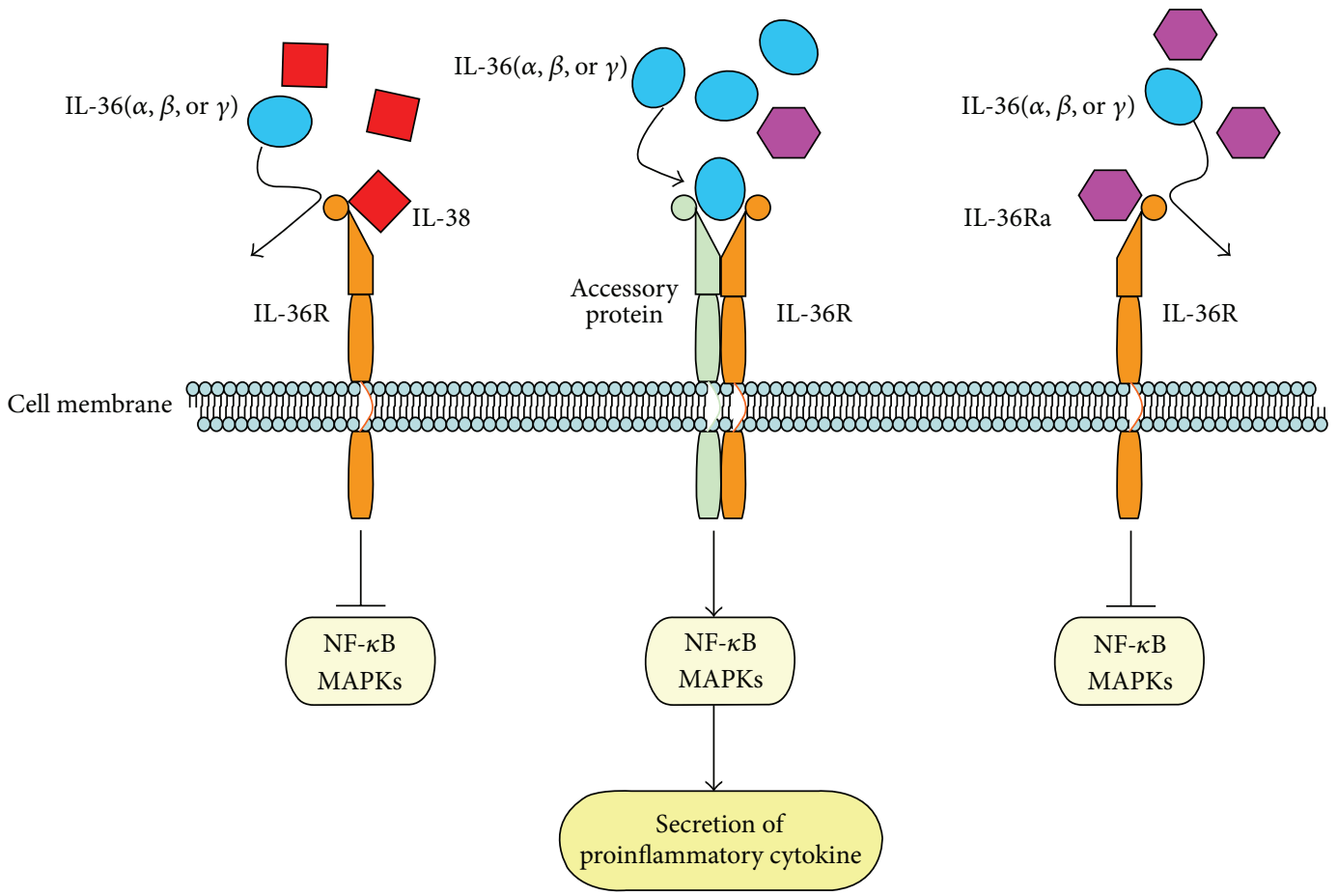

FIGURE 2: Receptor and signaling pathway of IL-38.

$[19,20]$. In line with the characteristics of IL-38 and the homology of IL-38 and IL-36Ra, it can be concluded that IL38 has a role in inflammatory disease by IL-36Ra pathwayrelated molecules (Figure 2). The biological function of IL38 is to inhibit IL-36 cytokine (IL-36 $\alpha$, IL-36 $\beta$, and IL$36 \gamma$ ) binding to IL-36R, similar to IL-36Ra. According to its activity as a receptor antagonist, IL-38 may have an antiinflammatory function. IL-38 might also be related to IL-1R and IL-18R signaling pathways, although there is no evidence regarding its role in these specific signaling pathways.

\section{Biological Activity of IL-38 and Related Cytokines}

Because of its homology with other IL-1F members, IL-38 is thought to have the biological activity of IL-1F members. IL1 cytokines are primarily proinflammatory cytokines as they stimulate the expression of genes associated with inflammation and immunological diseases. IL- $1 \alpha$ or IL- $1 \beta$ binds to its primary receptor IL-1RI, which recruits a second receptor subunit, IL-1RAcP. Formation of the receptor heterodimer induces biological responses typically involving the activation of $\mathrm{NF}-\kappa \mathrm{B}$ and mitogen-activated protein kinase (MAPK) pathways [21]. IL-1F6 (IL-36 $\alpha$ ), IL-1F8 (IL-36 $\beta$ ), and IL-1F9 (IL-36 $\gamma$ ) also activate NF- $\kappa$ B and MAPKs similar to IL-1. Therefore, most molecules involved in IL-1F-induced signaling, such as cytokines, chemokines, adhesion molecules, and enzymes, are mediators of inflammatory diseases $[22,23]$.

4.1. IL-1Ra. IL-1Ra (IL-1F3) is the receptor antagonist of IL-1, a protein composed of two major subunits, IL- $1 \alpha$ and IL- $1 \beta$ [24]. IL-1Ra is synthesized and released in response to the same stimuli that lead to IL-1 production. IL-1Ra, a potent anti-inflammatory cytokine, competitively inhibits stimulation by inflammatory mediators by binding to IL-1R1 and preventing the recruitment of IL-1RAcP. IL-1Ra is associated with severe autoimmune and inflammatory diseases such as periodontitis [25], vaginitis [26], non-Hodgkin's lymphoma [27], gastric cancer [28, 29], osteoarthritis [30], precancerous lesions [31], and inflammatory bowel diseases [32]. Deficiency of the IL-1-receptor antagonist (DIRA), caused by mutations in ILIRN, can lead to an autosomal recessive autoinflammatory disease. DIRA allows unopposed actions of IL-1, resulting in life-threatening excessive systemic IL-1mediated inflammation with skin and bone involvement [33]. A study by Korthagen et al. aimed to elucidate the influence of polymorphisms in IL1RN on idiopathic pulmonary fibrosis (IPF) susceptibility and mRNA expression. Polymorphisms of ILIRN manifested as a variable number tandem repeat (VNTR), which affected IL-1Ra mRNA expression, suggest that lower levels of IL-1Ra predispose to developing IPF [34]. In addition, IL-1RA VNTR may be associated with Parkinson's disease risk [35]. IL1RN may be a future novel therapeutic target with high specificity, low toxicity, and side effects for the treatment of specific diseases. It is important to enhance our understanding of ILIRN functions, such as its interaction with other genes and the influence of environmental factors on its production, to develop treatments with reduced side effects [34].

In addition, IL1Ra-deficient (IL-1Ra-/-) mice, good animal models for experimental studies, spontaneously develop several inflammatory diseases, resembling arthritis [36], aortitis [37], intervertebral disc degeneration [38], and psoriasis 
in humans due to unopposed excess IL-1 signaling. The current knowledge also suggested that IL-1Ra, an endogenous inhibitor of IL-1, related to alcoholic steatohepatitis [39], liver damage [40], lung damage [41], fat mass [42], and aqueousdeficient dry eye in autoimmune diseases [43].

4.2. IL-36Ra. IL-36Ra (IL-1F5) shares $44 \%$ homology with IL-1Ra and is an antagonist of IL-36 $\alpha$, IL-36 $\beta$, and IL-36 $\gamma$. IL$36 \mathrm{Ra}$ has a $\beta$-stranded trefoil structure, similar to other family members of IL-1, with a conserved hydrophobic core. IL36Ra binds to IL-1Rrp 2 and has biological effects on immune cells. The mechanism of IL-36Ra antagonism is analogous to IL-1Ra by forming a functional signaling complex. IL-36Ra protein starting at Val-2 is fully active and inhibits IL-36 $\alpha$, IL-36 $\beta$, and IL-36 $\gamma$. The A-X-Asp motif is conserved in all IL-1F members at the N-terminal, where Val-2 of IL-36Ra lies in this 9-amino acid conserved sequence. All four IL-36 cytokines lack a conventional signal sequence and function as extracellular cytokines although it is unclear how they are secreted [44]. In addition, IL-36Ra antagonist activity requires removal of the $\mathrm{N}$-terminal methionine present in the primary translation product [45]. More extensive Nterminal amino truncation of IL-36 $\alpha$, IL-36 $\beta$, and IL-36 $\gamma$ can dramatically increase their specific activities [45].

IL-36Ra plays a key role in innate and adaptive immunity by stimulating helper $\mathrm{T}$-cell responses and it is associated with many inflammatory diseases. Recessive homozygous mutations in IL36RN are the major cause for the development of generalized pustular psoriasis [46-49]. Mutations in IL36RN, including premature termination codon mutations, frameshift mutations, and substitutions of amino acid lead to incorrect folding of the IL-36Ra protein. These mutations inhibit the activity of IL-36Ra, thus failing to antagonize IL-36 signaling pathways and inducing inflammatory skin disease due to the high levels of IL-36 $\alpha$, IL-36 $\beta$, and IL-36 $\gamma$. Excessive IL-36 levels in the skin of mice lead to symptoms to human psoriasis. However, IL-36Ra-deficient mice develop the more serious pustular psoriasis. Therefore, treatment with a combination of IL-36Ra and IL-36R might improve psoriasis by inhibiting IL-36 stimulation and might be an ideal treatment strategy for inflammation of human skin. IL-36Ra functions as an anti-inflammatory cytokine in the brain [50] and enhances the hippocampal expression of IL4. This is a consequence of its interaction with the orphan receptor, single Ig IL-1R-related molecule (SIGIRR)/TIR8. Collectively, in vitro IL-4 mRNA and protein expression in glia induced by the interaction of IL-36Ra and SIGIRR/TIR8 play a critical role in its anti-inflammatory properties [5]. IL-36 cytokines also have a significant association in the pathogenesis of rheumatoid arthritis $[9,51,52]$, inflammatory lung diseases [53, 54], obesity [55], bile duct occlusion disorder, and chronic glomerulonephritis [56]. Data strongly suggest that IL-36Ra might be a useful treatment for IL-36related diseases.

4.3. $I L-38$. In recent years, scholars identified a novel $\mathrm{CD} 4^{+}$ T-cell subtype, which was different from T-helper 1 (Th1) and Th2 cells. These cells were named Th17 cells due to the expression of IL-17 and these discoveries have improved our understanding of inflammatory processes. Th17 cells are different from natural T-cell precursors, and the mature cells secrete a variety of cytokines such as IL-17 and IL-22 [57, 58]. Th17 plays an important role in a variety of autoimmune diseases and has an independent regulatory mechanism for their differentiation and development. Th17 is associated with the pathogenesis of systemic lupus erythematosus, rheumatoid arthritis, multiple sclerosis, psoriasis, inflammatory bowel disease, and autoimmune thyroid diseases [44]. Previous studies demonstrated the functions of IL-38 and Th17 cells by blocking the IL-1R, IL-18R, and IL-36R pathways [5]. These data suggested that the influence of IL-38 on Th17 cells was similar to blocking IL-1R and IL-36R pathways, which suppressed IL-17 and IL-22 secretion. Consistent with binding data and the suppression of IL-17 and IL-22, we suggest that IL-38 has similar biological effects on Th17 cells.

IL-38 gene polymorphisms are associated with psoriatic arthritis (PsA), ankylosing spondylitis (AS) [59-61], and cardiovascular disease [62], suggesting that IL-38 is strongly correlated with these inflammatory diseases. The frequencies of Th17 cells are significantly increased in the peripheral blood of patients with PsA and AS [8, 63-68]. In addition, the number of Th17 cells and serum IL-17 levels were strongly related to systemic disease activity both at the onset and during disease progression of PsA and AS [68]. IL-38 reduced the expression of C. albicans-induced IL-17 and IL-22 from peripheral blood mononuclear cells (PBMCs) by reducing the stimulation of proinflammatory cytokines in the tissues. A recent study reported that low concentrations of IL-38 were more effective than higher concentrations in inhibiting IL-17 and IL-22 production because higher concentrations modestly increased IL-22 [5].

Similar to IL-36Ra, blocking IL-38 suppressed C. albicans-induced Th17 cytokine production $[5,69]$. Both IL-38 and IL-36Ra inhibited the production of IL-17 and IL-22 by specifically binding to the cell surface-specific protein receptor IL-36R. However, neither IL-38 nor IL-36R functions as a classic receptor antagonist. In PBMCs, the dose-response suppression of IL-38 and IL-36Ra by IL-36 $\gamma$-derived IL- 8 was not similar to that of IL-1Ra. Neutrophils and T cells in inflammatory tissues are attracted by IL-8, a chemokine. IL38 decreased the production of proinflammatory cytokines similar to IL-36Ra $[5,70]$. In contrast, IL-38 and IL-36Ra have parallel effects on the production of lipopolysaccharideinduced IL-6 from dendritic cells (DCs), inducing a twofold increase [5]. IL-6 has two adverse effects on immune cells: IL-6 is proinflammatory but also suppresses inflammation in tissues injured by burns or other damages.

IL-1Ra and IL-38 have a comparable dose-effect regarding their antagonist activities and function as classic receptor antagonists; the higher the concentration of IL-22, the stronger its inhibition. Compared with IL-1Ra and IL-38, IL36Ra does not behave as a typical receptor antagonist. IL-38 and IL-36Ra function as antagonists at high concentrations, but at low concentrations, they inhibit the binding of coreceptors. Thus, IL-38 and IL-36Ra are defined as partial receptor antagonists, although they mimic the effects of IL-1Ra on the production of inflammatory cytokines. 


\section{Future Perspectives}

IL-1 and most related family members are primarily proinflammatory cytokines that induce the expression of genes associated with inflammatory diseases. Only IL-37 acts as an anti-inflammatory cytokine. The binding of IL-1Ra and IL-36Ra to their receptor reduces inflammation by blocking the binding of receptor ligands. The production of fungalinduced IL-17, IL-22, and IL-36 $\gamma$-derived IL-8 was decreased by IL-38, which may play an important anti-inflammatory role in inflammatory diseases. Many articles have demonstrated that IL-1Ra and IL-36Ra are associated with arthritis and psoriasis, respectively. In addition, IL-38 can specifically bind to IL-36R, similar to IL-36Ra. IL-36 cytokine has significant in vivo effects on DCs and T cells in human immune responses via its role in the differentiation of inflammatory Th1 cells [70-72].

In conclusion, the current knowledge supports the concept that IL-38 may be closely associated with IL-36-mediated inflammatory diseases. Thus far, the IL-1 receptor antagonist anakinra, the soluble decoy receptor rilonacept, and the neutralizing monoclonal anti-IL-1 $\beta$ antibody canakinumab have been approved as IL-1-targeting agents for the treatment of specific diseases. Another study demonstrated the beneficial use of a monoclonal antibody directed against the IL-1 receptor and a neutralizing anti-IL- $\alpha$ antibody in clinical trials [73]. The IL-38-related signaling pathway is poorly understood and requires further study. Furthermore, the function and mechanism of IL-38-related diseases remain elusive and awaits elucidation. The increasing knowledge of the mechanisms that regulate chronic inflammatory conditions such as rheumatoid arthritis may provide a potential strategy for the development of anti-inflammatory treatments for autoimmune diseases and establish a theoretical basis for clinical trials and drug development.

\section{Conflict of Interests}

The authors declare that there is no conflict of interests regarding the publication of this paper.

\section{Acknowledgments}

This work was supported by the grants from the National Natural Science Foundation of China (81370166), the Zhejiang Provincial Natural Science Foundation of China (LY13H090014), the Scientific Research Fund of Zhejiang Provincial Education Department (Y201327689), the Scientific Innovation Team Project of Ningbo (2011B82014), the Social Development Program of Ningbo (2013C50054), and the Scientific Research Foundation of Graduate School of Ningbo University (G14036) and sponsored by K. C. Wong Magna Fund in Ningbo University.

\section{References}

[1] C. A. Dinarello, "Interleukin-1 in the pathogenesis and treatment of inflammatory diseases," Blood, vol. 117, no. 14, pp. 37203732, 2011.
[2] C. Dinarello, W. Arend, and J. Sims, "IL-1 family nomenclature," Nature Immunology, vol. 11, article 973, 2010.

[3] H. Lin, A. S. Ho, D. Haley-Vicente et al., "Cloning and characterization of IL-1HY2, a novel interleukin-1 family member," The Journal of Biological Chemistry, vol. 276, no. 23, pp. 2059720602, 2001.

[4] J. T. Bensen, P. A. Dawson, J. C. Mychaleckyj, and D. W. Bowden, "Identification of a novel human cytokine gene in the interleukin gene cluster on chromosome 2q12-14," Journal of Interferon and Cytokine Research, vol. 21, no. 11, pp. 899-904, 2001.

[5] F. L. van de Veerdonk, A. K. Stoeckman, G. Wu et al., "IL-38 binds to the IL-36 receptor and has biological effects on immune cells similar to IL-36 receptor antagonist," Proceedings of the National Academy of Sciences of the United States of America, vol. 109, no. 8, pp. 3001-3005, 2012.

[6] M. J. H. Nicklin, J. L. Barton, M. Nguyen, M. G. FitzGerald, G. W. Duff, and K. Kornman, "A sequence-based map of the nine genes of the human interleukin-1 cluster," Genomics, vol. 79, no. 5, pp. 718-725, 2002.

[7] S. Kumar, P. C. McDonnell, R. Lehr et al., "Identification and initial characterization of four novel members of the interleukin-1 family," The Journal of Biological Chemistry, vol. 275, no. 14, pp. 10308-10314, 2000.

[8] H. Shen, J. C. Goodall, and J. S. Hill Gaston, "Frequency and phenotype of peripheral blood Th17 cells in ankylosing spondylitis and rheumatoid arthritis," Arthritis and Rheumatism, vol. 60, no. 6, pp. 1647-1656, 2009.

[9] M. S. Gresnigt and F. L. van de Veerdonk, "Biology of IL-36 cytokines and their role in disease," Seminars in Immunology, vol. 25, no. 6, pp. 458-465, 2013.

[10] H. E. Barksby, S. R. Lea, P. M. Preshaw, and J. J. Taylor, “The expanding family of interleukin-1 cytokines and their role in destructive inflammatory disorders," Clinical and Experimental Immunology, vol. 149, no. 2, pp. 217-225, 2007.

[11] B. A. Charles, A. Doumatey, H. Huang et al., "The roles of IL-6, IL-10, and IL-1RA in obesity and insulin resistance in AfricanAmericans," Journal of Clinical Endocrinology and Metabolism, vol. 96, no. 12, pp. E2018-E2022, 2011.

[12] M. F. Nold, C. A. Nold-Petry, J. A. Zepp, B. E. Palmer, P. Bufler, and C. A. Dinarello, "IL-37 is a fundamental inhibitor of innate immunity," Nature Immunology, vol. 11, no. 11, pp. 1014-1022, 2010.

[13] V. Carriere, L. Roussel, N. Ortega et al., "IL-33, the IL-1-like cytokine ligand for ST2 receptor, is a chromatin-associated nuclear factor in vivo," Proceedings of the National Academy of Sciences of the United States of America, vol. 104, no. 1, pp. 282287, 2007.

[14] F. Xu, S. Cheng, and Y. Luo, "DRB1 gene bioinformatics analysis of sheep," Biotechnology Bulletin, no. 1, pp. 113-118, 2011.

[15] N. V. Kumar, M. E. Rani, R. Gunaseeli, N. D. Kannan, and J. Sridhar, "Modeling and structural analysis of cellulases using Clostridium thermocellum as template," Bioinformation, vol. 8, no. 22, pp. 1105-1110, 2012.

[16] C. Geourjon and G. Deleage, "SOPMA: significant improvements in protein secondary structure prediction by consensus prediction from multiple alignments," Computer Applications in the Biosciences, vol. 11, no. 6, pp. 681-684, 1995.

[17] S. J. Busfield, C. A. Comrack, G. Yu et al., "Identification and gene organization of three novel members of the IL-1 family on human chromosome 2," Genomics, vol. 66, no. 2, pp. 213-216, 2000 . 
[18] D. E. Smith, B. R. Renshaw, R. R. Ketchem, M. Kubin, K. E. Garka, and J. E. Sims, "Four new members expand the interleukin-1 superfamily," The Journal of Biological Chemistry, vol. 275, no. 2, pp. 1169-1175, 2000.

[19] T. T. Chowdhury, S. Arghandawi, J. Brand et al., "Dynamic compression counteracts IL-1 $\beta$ induced inducible nitric oxide synthase and cyclo-oxygenase- 2 expression in chondrocyte/ agarose constructs," Arthritis Research and Therapy, vol. 10, no. 2, article R35, 2008.

[20] E. I. Boesen, "Chronic elevation of IL-1 $\beta$ induces diuresis via a cyclooxygenase 2-mediated mechanism," The American Journal of Physiology-Renal Physiology, vol. 305, no. 2, pp. F189-F198, 2013.

[21] L. A. J. O’Neill, “The interleukin-1 receptor/Toll-like receptor superfamily: 10 years of progress," Immunological Reviews, vol. 226, no. 1, pp. 10-18, 2008.

[22] J. E. Towne, K. E. Garka, B. R. Renshaw, G. D. Virca, and J. E. Sims, "Interleukin (IL)-1F6, IL-1F8, and IL-1F9 signal through IL-1Rrp2 and IL-1RAcP to activate the pathway leading to NF$\kappa \mathrm{B}$ and MAPKs," The Journal of Biological Chemistry, vol. 279, no. 14, pp. 13677-13688, 2004.

[23] A. Dunne and L. A. J. O’Neill, “The interleukin-1 receptor/Tolllike receptor superfamily: signal transduction during inflammation and host defense," Science's STKE, vol. 2003, no. 171, p. re3, 2003.

[24] C. A. Dinarello, "Immunological and inflammatory functions of the interleukin-1 family," Annual Review of Immunology, vol. 27, pp. 519-550, 2009.

[25] C. Ding, L. Zhao, Y. Sun, L. Li, and Y. Xu, "Interleukin-1 receptor antagonist polymorphism (rs2234663) and periodontitis susceptibility: a meta-analysis," Archives of Oral Biology, vol. 57, no. 6, pp. 585-593, 2012.

[26] R. N. Fichorova, J.-J. Lai, J. L. Schwartz, D. H. Weiner, C. K. Mauck, and M. M. Callahan, "Baseline variation and associations between subject characteristics and five cytokine biomarkers of vaginal safety among healthy non-pregnant women in microbicide trials," Cytokine, vol. 55, no. 1, pp. 134-140, 2011.

[27] H. D. Hosgood, M. P. Purdue, S. S. Wang et al., "A pooled analysis of three studies evaluating genetic variation in innate immunity genes and non-Hodgkin lymphoma risk," The British Journal of Haematology, vol. 152, no. 6, pp. 721-726, 2011.

[28] H. Xue, B. Lin, P. Ni, H. Xu, and G. Huang, "Interleukin-1B and interleukin-1 RN polymorphisms and gastric carcinoma risk: a meta-analysis," Journal of Gastroenterology and Hepatology (Australia), vol. 25, no. 10, pp. 1604-1617, 2010.

[29] C. Persson, P. Canedo, J. C. MacHado, E. M. El-Omar, and D. Forman, "Polymorphisms in inflammatory response genes and their association with gastric cancer: a HuGE systematic review and meta-analyses," American Journal of Epidemiology, vol. 173, no. 3, pp. 259-270, 2011.

[30] H. J. Kerkhof, M. Doherty, N. K. Arden et al., "Large-scale metaanalysis of interleukin-1 $\beta$ and interleukin-1 receptor antagonist polymorphisms on risk of radiographic hip and knee osteoarthritis and severity of knee osteoarthritis," Osteoarthritis and Cartilage, vol. 19, no. 3, pp. 265-271, 2011.

[31] B. Peleteiro, N. Lunet, C. Carrilho et al., "Association between cytokine gene polymorphisms and gastric precancerous lesions: systematic review and meta-analysis," Cancer Epidemiology Biomarkers and Prevention, vol. 19, no. 3, pp. 762-776, 2010.

[32] V. D. Corleto, C. Pagnini, G. Margagnoni et al., "IL-1 $\beta-511$ and IL-1RN $* 2$ polymorphisms in inflammatory bowel disease: an Italian population study and meta-analysis of European studies," Digestive and Liver Disease, vol. 42, no. 3, pp. 179-184, 2010.

[33] I. Aksentijevich, S. L. Masters, P. J. Ferguson et al., "An autoinflammatory disease with deficiency of the interleukin-1-receptor antagonist," The New England Journal of Medicine, vol. 360, no. 23, pp. 2426-2437, 2009.

[34] N. M. Korthagen, C. H. M. van Moorsel, K. M. Kazemier, H. J. T. Ruven, and J. C. Grutters, "IL1RN genetic variations and risk of IPF: a meta-analysis and mRNA expression study," Immunogenetics, vol. 64, no. 5, pp. 371-377, 2012.

[35] K. Chu, X. Zhou, and B. Y. Luo, "Cytokine gene polymorphisms and Parkinson's disease: a meta-analysis," Canadian Journal of Neurological Sciences, vol. 39, no. 1, pp. 58-64, 2012.

[36] W. Hur, M.-L. Cho, S. K. Yoon et al., "Adenoviral delivery of IL-1 receptor antagonist abrogates disease activity during the development of autoimmune arthritis in IL-1 receptor antagonistdeficient mice," Immunology Letters, vol. 106, no. 2, pp. 154-162, 2006.

[37] K. Isoda, T. Matsuki, H. Kondo, Y. Iwakura, and F. Ohsuzu, "Deficiency of interleukin-1 receptor antagonist induces aortic valve disease in BALB/c Mice," Arteriosclerosis, Thrombosis, and Vascular Biology, vol. 30, no. 4, pp. 708-715, 2010.

[38] K. L. Phillips, N. Jordan-Mahy, M. J. Nicklin, and C. L. Le Maitre, "Interleukin-1 receptor antagonist deficient mice provide insights into pathogenesis of human intervertebral disc degeneration," Annals of the Rheumatic Diseases, vol. 72, no. 11, pp. 1860-1867, 2013.

[39] J. Petrasek, S. Bala, T. Csak et al., "IL-1 receptor antagonist ameliorates inflammasome-dependent alcoholic steatohepatitis in mice," Journal of Clinical Investigation, vol. 122, no. 10, pp. 3476-3489, 2012.

[40] E. Conrad, T. K. Resch, P. Gogesch et al., "Protection against RNA-induced liver damage by myeloid cells requires type I interferon and IL-1 receptor antagonist in mice," Hepatology, vol. 59, no. 4, pp. 1555-1563, 2014.

[41] S. Herold, T. S. Tabar, H. Janßen et al., "Exudate macrophages attenuate lung injury by the release of IL-1 receptor antagonist in gram-negative pneumonia," The American Journal of Respiratory and Critical Care Medicine, vol. 183, no. 10, pp. 1380-1390, 2011.

[42] E. Somm, E. Henrichot, A. Pernin et al., "Decreased fat mass in interleukin-1 receptor antagonist-deficient mice: Impact on adipogenesis, food intake, and energy expenditure," Diabetes, vol. 54, no. 12, pp. 3503-3509, 2005.

[43] T. Vijmasi, F. Y. T. Chen, Y. T. Chen, M. Gallup, and N. McNamara, "Topical administration of interleukin-1 receptor antagonist as a therapy for aqueous-deficient dry eye in autoimmune disease," Molecular Vision, vol. 19, pp. 1957-1965, 2013.

[44] J. E. Sims and D. E. Smith, "The IL-1 family: regulators of immunity," Nature Reviews Immunology, vol. 10, no. 2, pp. 89-102, 2010.

[45] J. E. Towne, B. R. Renshaw, J. Douangpanya et al., "Interleukin36 (IL-36) ligands require processing for full agonist (IL$36 \alpha$, IL-36 $\beta$, and IL-36 $\gamma$ ) or antagonist (IL-36Ra) activity," The Journal of Biological Chemistry, vol. 286, no. 49, pp. 4259442602, 2011.

[46] S. Marrakchi, P. Guigue, B. R. Renshaw et al., "Interleukin-36receptor antagonist deficiency and generalized pustular psoriasis," The New England Journal of Medicine, vol. 365, no. 7, pp. 620-628, 2011. 
[47] M. Farooq, H. Nakai, A. Fujimoto et al., "Mutation analysis of the IL36RN gene in 14 Japanese patients with generalized pustular psoriasis," Human Mutation, vol. 34, no. 1, pp. 176-183, 2013.

[48] K. Sugiura, T. Takeichi, M. Kono et al., "A novel IL36RN/IL1F5 homozygous nonsense mutation, p.Arg10X, in a Japanese patient with adult-onset generalized pustular psoriasis," British Journal of Dermatology, vol. 167, no. 3, pp. 699-701, 2012.

[49] N. Kanazawa, T. Nakamura, N. Mikita, and F. Furukawa, "Novel IL36RN mutation in a Japanese case of early onset generalized pustular psoriasis," Journal of Dermatology, vol. 40, no. 9, pp. 749-751, 2013.

[50] C. Costelloe, M. Watson, A. Murphy et al., "IL-1F5 mediates anti-inflammatory activity in the brain through induction of IL-4 following interaction with SIGIRR/TIR8," Journal of Neurochemistry, vol. 105, no. 5, pp. 1960-1969, 2008.

[51] D. Magne, G. Palmer, J. L. Barton et al., "The new IL-1 family member IL-1F8 stimulates production of inflammatory mediators by synovial fibroblasts and articular chondrocytes," Arthritis Research and Therapy, vol. 8, no. 3, article R80, 2006.

[52] F. L. van de Veerdonk and M. G. Netea, "New insights in the immunobiology of IL-1 family members," Frontiers in Immunology, vol. 4, article 167, 2013.

[53] C. Lamacchia, G. Palmer, E. Rodriguez et al., "The severity of experimental arthritis is independent of IL-36 receptor signaling," Arthritis Research and Therapy, vol. 15, no. 2, article R38, 2013.

[54] R. A. Ramadas, S. L. Ewart, Y. Iwakura, B. D. Medoff, and A. M. LeVine, "IL-36 $\alpha$ exerts pro-inflammatory effects in the lungs of mice," PLoS ONE, vol. 7, no. 9, Article ID e45784, 2012.

[55] E. J. P. Van Asseldonk, R. Stienstra, T. B. Koenen et al., "The effect of the interleukin-1 cytokine family members IL-1F6 and IL-1F8 on adipocyte differentiation," Obesity, vol. 18, no. 11, pp. 2234-2236, 2010.

[56] J. Leonhardt, M. Stanulla, R. Von Wasielewski et al., "Gene expression profile of the infective murine model for biliary atresia," Pediatric Surgery International, vol. 22, no. 1, pp. 84-89, 2006.

[57] S. Burgler, N. Ouaked, C. Bassin et al., "Differentiation and functional analysis of human TH17 cells," Journal of Allergy and Clinical Immunology, vol. 123, no. 3, pp. 588.e7-595.e7, 2009.

[58] L. E. Harrington, R. D. Hatton, P. R. Mangan et al., "Interleukin 17-producing $\mathrm{CD}^{+}$effector T cells develop via a lineage distinct from the T helper type 1 and 2 lineages," Nature Immunology, vol. 6, no. 11, pp. 1123-1132, 2005.

[59] P. Rahman, S. Sun, L. Peddle et al., "Association between the interleukin-1 family gene cluster and psoriatic arthritis," Arthritis and Rheumatism, vol. 54, no. 7, pp. 2321-2325, 2006.

[60] C.-T. Chou, A. E. Timms, J. C. C. Wei, W. C. Tsai, B. P. Wordsworth, and M. A. Brown, "Replication of association of IL1 gene complex members with ankylosing spondylitis in Taiwanese Chinese," Annals of the Rheumatic Diseases, vol. 65, no. 8, pp. 1106-1109, 2006.

[61] Z. S. Guo, C. Li, Z. M. Lin et al., "Association of IL-1 gene complex members with ankylosing spondylitis in Chinese Han population," International Journal of Immunogenetics, vol. 37, no. 1, pp. 33-37, 2010.

[62] A. Dehghan, J. Dupuis, M. Barbalic et al., "Meta-analysis of genome-wide association studies in $>80000$ subjects identifies multiple loci for C-reactive protein levels," Circulation, vol. 123, no. 7, pp. 731-738, 2011.
[63] P. Bowness, A. Ridley, J. Shaw et al., "Th17 cells expressing $\mathrm{KIR} 3 \mathrm{DL} 2^{+}$and responsive to HLA-B27 homodimers are increased in ankylosing spondylitis," The Journal of Immunology, vol. 186, no. 4, pp. 2672-2680, 2011.

[64] Y. Mei, F. Pan, J. Gao et al., "Increased serum IL-17 and IL-23 in the patient with ankylosing spondylitis," Clinical Rheumatology, vol. 30, no. 2, pp. 269-273, 2011.

[65] D. Wendling, "IL-23 and IL-17 in ankylosing spondylitis," Rheumatology International, vol. 30, no. 11, p. 1547, 2010.

[66] X. Wang, Z. Lin, Q. Wei, Y. Jiang, and J. Gu, "Expression of IL-23 and IL-17 and effect of IL-23 on IL-17 production in ankylosing spondylitis," Rheumatology International, vol. 29, no. 11, pp. 1343-1347, 2009.

[67] C. Jandus, G. Bioley, J.-P. Rivals, J. Dudler, D. Speiser, and P. Romero, "Increased numbers of circulating polyfunctional Th17 memory cells in patients with seronegative spondylarthritides," Arthritis and Rheumatism, vol. 58, no. 8, pp. 2307-2317, 2008.

[68] J. Leipe, M. Grunke, C. Dechant et al., "Role of Th17 cells in human autoimmune arthritis," Arthritis \& Rheumatism, vol. 62, no. 10, pp. 2876-2885, 2010.

[69] M. S. Gresnigt, B. Rösler, C. W. M. Jacobs et al., “The IL-36 receptor pathway regulates Aspergillus fumigatus-induced Th1 and Th17 responses," European Journal of Immunology, vol. 43, no. 2, pp. 416-426, 2013.

[70] S. Vigne, G. Palmer, C. Lamacchia et al., "IL-36R ligands are potent regulators of dendritic and T cells," Blood, vol. 118, no. 22, pp. 5813-5823, 2011.

[71] S. Mutamba, A. Allison, Y. Mahida, P. Barrow, and N. Foster, "Expression of IL-1Rrp2 by human myelomonocytic cells is unique to DCs and facilitates DC maturation by IL-1F8 and IL1F9," European Journal of Immunology, vol. 42, no. 3, pp. 607-617, 2012.

[72] S. Vigne, G. Palmer, P. Martin et al., "IL-36 signaling amplifies Th1 responses by enhancing proliferation and Th1 polarization of naive CD4 ${ }^{+}$T cells," Blood, vol. 120, no. 17, pp. 3478-3487, 2012.

[73] C. A. Dinarello and J. W. M. van der Meer, "Treating inflammation by blocking interleukin-1 in humans," Seminars in Immunology, vol. 25, no. 6, pp. 469-484, 2013. 


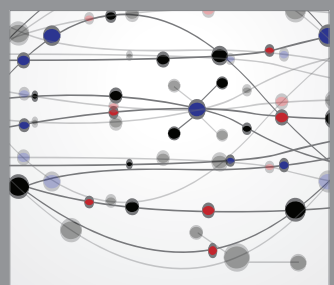

The Scientific World Journal
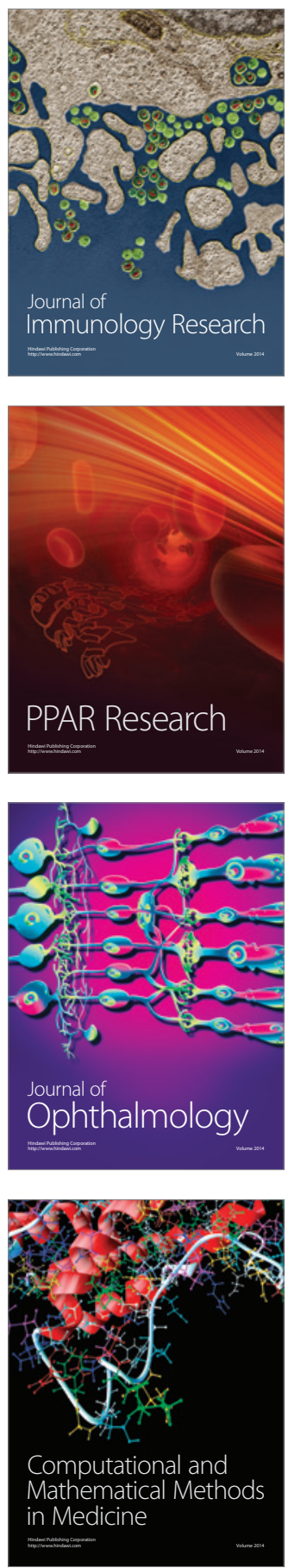

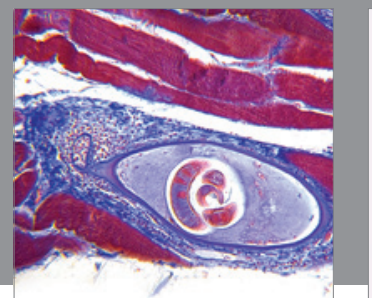

Gastroenterology

Research and Practice
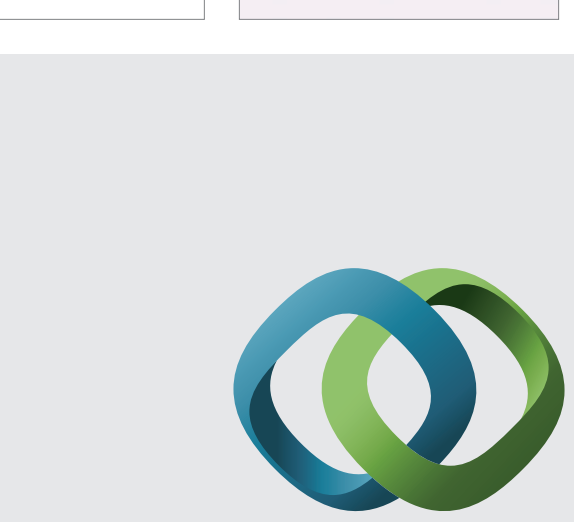

\section{Hindawi}

Submit your manuscripts at

http://www.hindawi.com
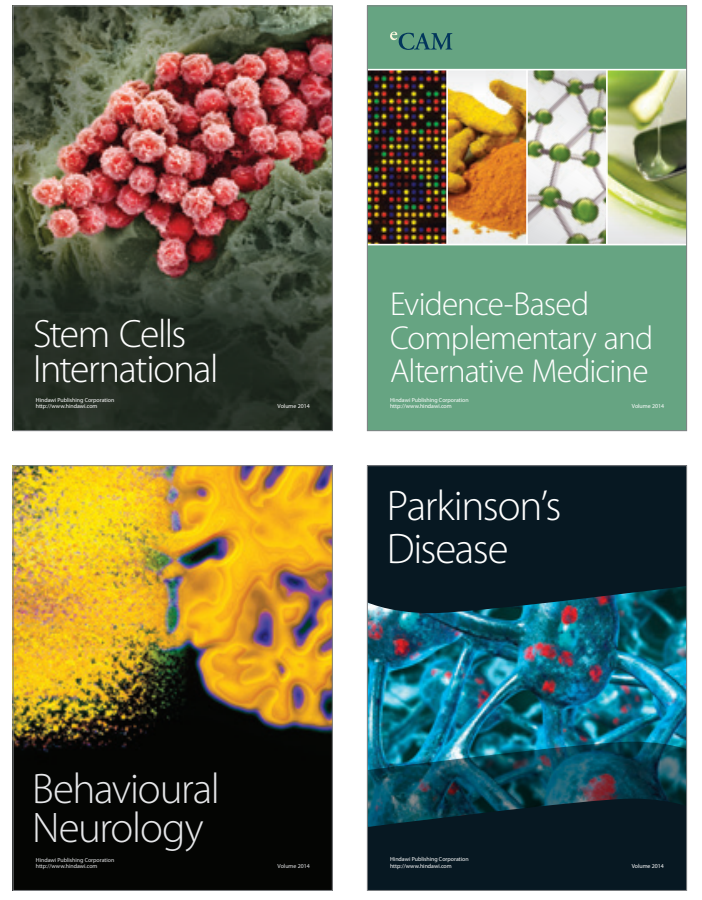
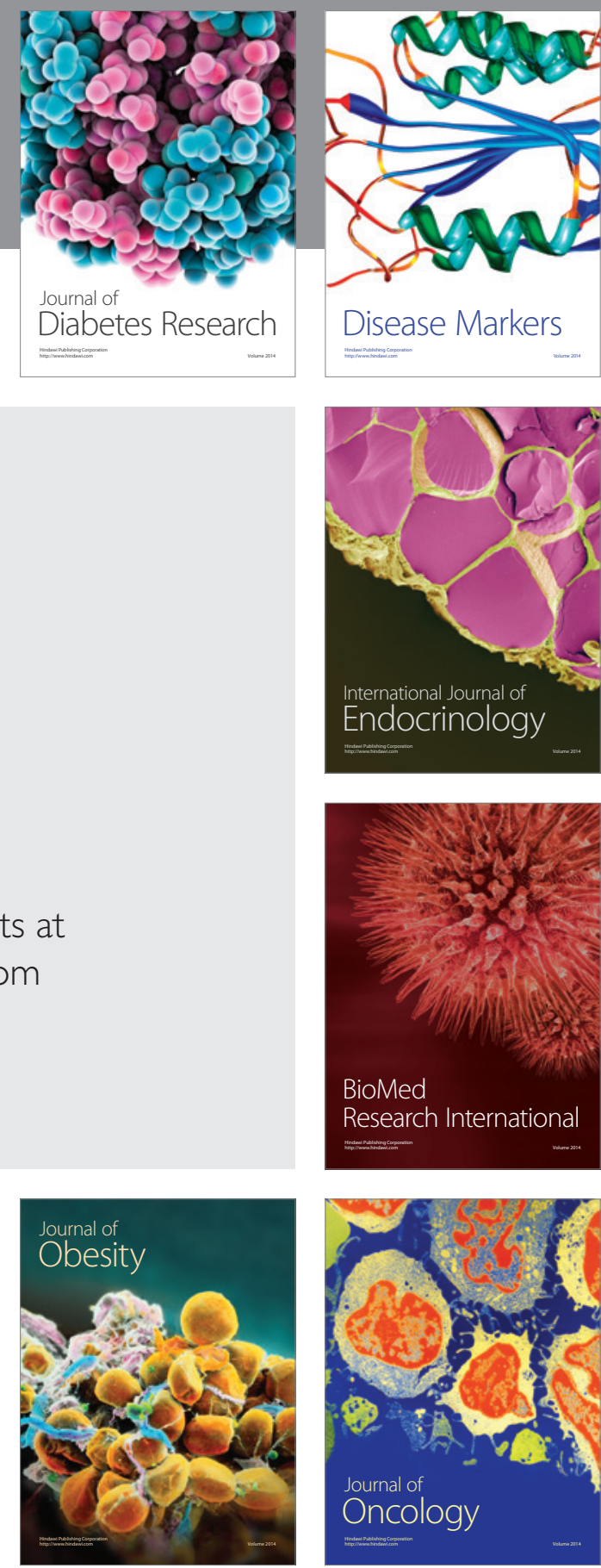

Disease Markers
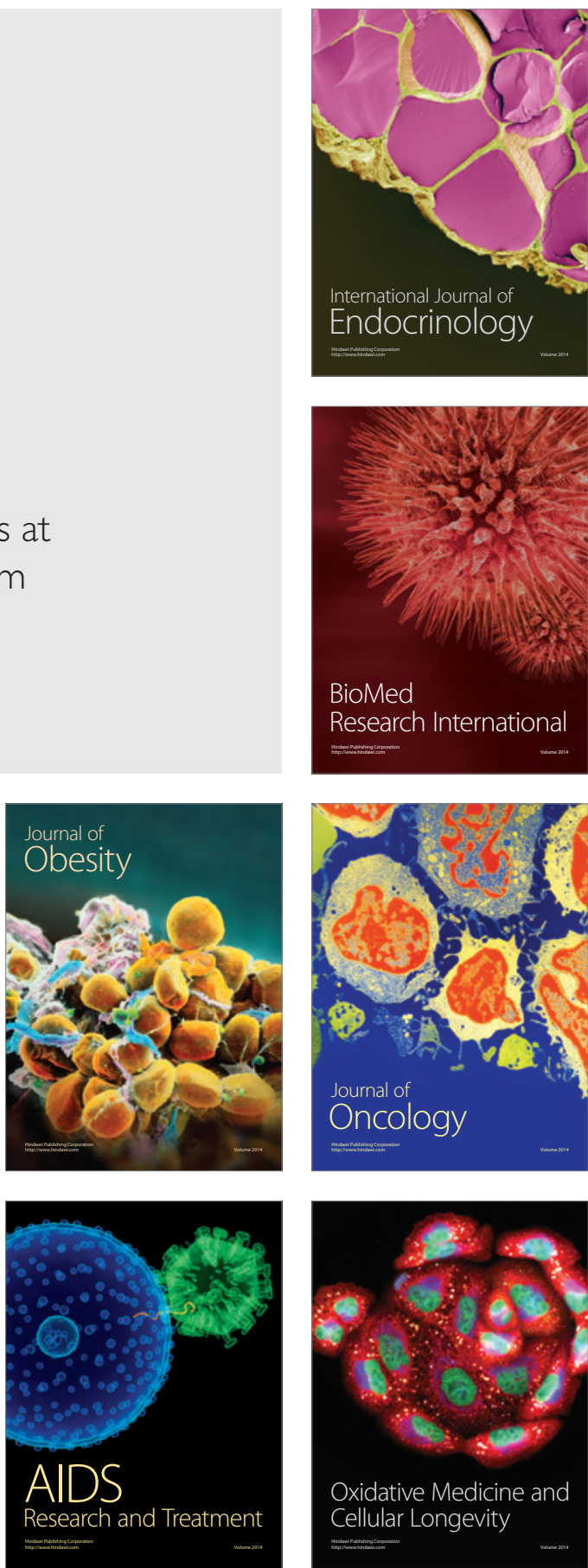